\title{
Detection of Smoking Induced Emphysema: Visual Scoring versus Computerised Algorithms
}

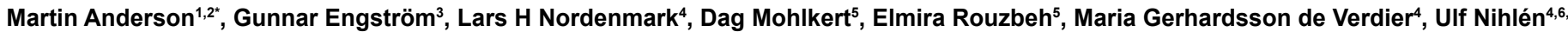
Thomas Fehniger ${ }^{7}$, Magnus Dahlbäck ${ }^{4}$ and Magnus Svartengren ${ }^{1,8}$

${ }^{1}$ Department of Public Health Sciences, Karolinska Institutet, Stockholm, Sweden

${ }^{2}$ Division of Clinical Physiology, Karolinska University Hospital, Huddinge, Sweden

${ }^{3}$ Department of Clinical Sciences, Lund University, Lund, Sweden

${ }^{4}$ AstraZeneca R\&D Mölndal, Mölndal, Sweden

${ }^{5}$ Department of Radiology, Södersjukhuset, Stockholm, Sweden

${ }^{6}$ Department of Respiratory Medicine and Allergology, Lund University, Sweden

${ }^{7}$ Department of Biomedical Engineering, Lunds Technical University, Lund, Sweden

${ }^{8}$ Occupational and Environmental Medicine, Uppsala University, Uppsala, Sweden

\begin{abstract}
Purpose: Computed tomography (CT) has been applied to assess signs of early disease in a population study. Comparisons were made of histogram based methods to quantitatively determine lung density; relative area of emphysema below -910 and -950 Hounsfield units, and 15th percentile density (RA -910, RA -950 and PD15), as well as visual assessment of computed tomography (CT) images, to lung function indices in a population based study of smokers and non-smokers.
\end{abstract}

Methods: 138 subjects from a study of lung function in COPD were included in the study. Computerised assessments and visual scoring were used to analyse CT scans of different regions of identifying subjects with emphysema.

Results: Subjects visually diagnosed with centrilobular emphysema had significantly lower lung density $(n=27$, PD15=-932 HU, RA-950=6.6\%) compared to subjects without emphysema ( $n=106, P D 15=-917$ HU, RA-950=2.3\%). In the group with low PD15, the proportion with visually determined centrilobular emphysema was $38 \%$, compared to $15 \%$ in the groups with high PD15.

Conclusion: Evaluation of patterns of lung attenuation by automated assessment and visual scoring provided similar classifications of disease in patients with mild COPD but differed in identifying regions of low density in healthy subjects. Visual assessment showed better correlation to both lung function and smoking habits than quantitative measures in this study. Quantitative measures should be used in the upper third of the lungs to detect smoking induced emphysema. Measurements of early attenuation changes within healthy subjects may require additional measures of validation by radiologists by visual assessment.

Keywords: COPD; Emphysema; Computed tomography

\section{Introduction}

Chronic obstructive pulmonary disease (COPD) is a major and rising public health risk and the severity of airflow limitation is still a core element in diagnosis, assessment, and therapeutic management [1]. However, emerging data on COPD reveal substantial complexity, and it is generally accepted that the early pathological changes in COPD are not captured by spirometry only. Thus, a better understanding of the intricacy of COPD is important to improve current clinical practice and advance biomedical research and drug development. CT data should add another dimension into the description of COPD types and their progression

Emphysema is often seen as co-morbidity to COPD and could even be regarded as a specific phenotype. CT imaging of the chest can be used to describe different structural expressions of COPD, as well as broad pathogenic sequences (such as: large airway disease, small airway disease, gas trapping and unique patterns of emphysema).

The speed and the low cost of the computerised quantitative CT methods are major advantages in studies with big numbers of CT scans. Furthermore, they are free from individual judgement bias. However, visual assessment of the pattern of emphysema and of airways disease, as well as of large airway abnormalities may provide information not readily assessed by current quantitative methods.

Although a useful tool, there is currently no standard for these computerised techniques. Knowledge on to what extent these measures reflect actual COPD associated emphysema and correlates with other measures of the disease are increasing rapidly. Efforts have been made to find optimum thresholds [2], to use quantitative measures in indices [3] as well as more direct comparisons to lung function parameters [4]. Even though official guidelines do not exist the field was summarised in a workshop providing some clear recommendations [5] and reviewed recently [6].

The primary purpose of the present study was to compare computerised assessments and objective visual scoring of CT scans in twins with and without COPD. We also analysed the associations between CT emphysema and results from lung function tests with control for the influence of potential confounders such as sex, age, BMI, and tobacco consumption.

*Corresponding author: Martin Anderson, Division of clinical physiology, Department of Laboratory Medicine (LABMED), H5, Karolinska Universitetssjukhuset, Huddinge C1 88, 14186 Stockholm, Sweden, E-mail: martin.anderson5091@gmail.com

Received July 20, 2014; Accepted October 26, 2015; Published October 30, 2015

Citation: Anderson M, Engström G, Nordenmark LH, Mohlkert D, Rouzbeh E, et al. (2015) Detection of Smoking Induced Emphysema: Visual Scoring versus Computerised Algorithms. J Pulm Respir Med 5: 291. doi:10.4172/2161105X.1000291

Copyright: (c) 2015 Anderson M, et al. This is an open-access article distributed under the terms of the Creative Commons Attribution License, which permits unrestricted use, distribution, and reproduction in any medium, provided the original author and source are credited. 


\section{Methods}

\section{Study population}

All subjects were twins retrieved from the Swedish Twin Registry (STR), containing information on more than 80,000 twin pairs. Between 1998 and 2002, all living twins in the STR born in 1958 or earlier were contacted using a computer-assisted telephone interview [7], including a checklist of common diseases and respiratory symptoms, as well as smoking habits. From this telephone interview, 1,030 twins (in 515 pairs) were invited to participate in measurements of lung function [8]. The study was approved by the Ethical Committee at Karolinska Institute (\# 03-461).

In total, 392 twins accepted the invitation to participate, and following spirometry screening 139 subjects with a $\mathrm{FEV}_{1} / \mathrm{VC}$ ratio 5 units below the predicted value, or $\mathrm{FEV}_{1}$ below $90 \%$ of the predicted value were selected for CT. The $\mathrm{FEV}_{1} / \mathrm{VC}$-ratio 5 percent units below predicted corresponds well with the fixed GOLD ratio in middle ages, but is age corrected (since the predicted value is) so that overestimation of COPD in the elderly could be avoided. Also twin siblings to these with impaired lung function were selected for computed tomography. After the exclusion of five subjects with poor quality or incomplete data, 133 subjects remained. The selection of subjects was initially conducted for a heritability study as described previously, in a manner that disease concordant and discordant twins were prioritized over symptom-free twin pairs [9].

\section{Image acquisition}

Inspiratory CT image data were obtained in all subjects using a 4 slice a Siemens Volume Zoom CT scanner (Siemens Medical Solutions, Erlangen, Germany) in two modes:

1) A continuous helical scan $(140 \mathrm{kV}, 24-29 \mathrm{mAs}, 750 \mathrm{~ms}$ rotation time) from apex to base with $5 \mathrm{~mm}$ axial slices reconstructed using a standard algorithm (B30s kernel).

2) Discrete $1 \mathrm{~mm}$ axial HRCT-slices $(140 \mathrm{kV}, 100 \mathrm{mAS}, 500 \mathrm{~ms}$ rotation time) at three different levels; through the apices, at the hilar level and through the bases of the lungs, respectively, reconstructed using a B70f kernel.

The protocol was optimised for picture quality given the radiation constraints in this study including healthy volunteers. All images were stored electronically in the hospital PACS (picture archiving and communication system).

\section{CT densitometry}

Quantitative assessment of CT lung density was performed using the VIDA Apollo software version 1.1 (VIDA Diagnostics, Inc, Coralville, IA, USA). Attenuation in the lung is expressed in Hounsfield units (HU), where zero $\mathrm{HU}$ corresponds to the attenuation of water and $-1000 \mathrm{HU}$ to air. The $15^{\text {th }}$ percentile density (PD15), i.e. the HU value below which $15 \%$ of the lowest attenuation values are distributed, may also be expressed as density in $\mathrm{g} / \mathrm{L}$ by adding 1000 . The percentage of the lung volume with attenuation below the cut off values -910 $\mathrm{HU}$ and -950 HU (RA-910 and RA-950), as well as PD15 were calculated for the entire lungs, as well as separately for the upper, middle, and lower thirds of the lungs using the volumetric scan.

\section{Visual assessment of CT scans}

Visual assessment was independently performed by two radiologists. The continuous $5 \mathrm{~mm}$ helical images (with edge enhancement) and the discrete HRCT-slices were viewed simultaneously on 30" wide Eizo Rx430 screens with parenchymal window settings (width $1700 \mathrm{HU}$, center $-400 \mathrm{HU}$ ). The radiologists, used to protocols with higher radiation doses judged the difference between clinical routine protocol and the one used in the study as negligible. Subject scans were individually classified as showing a predominant pattern of the parenchymal features: 1) normal, without areas of low attenuation; 2) centrilobular emphysema (CE); 3) distended or both distended and with CE. The term "distended" was used for describing low attenuation with a pattern that seemed to be due to hyperinflation of the lung rather than loss of parenchyma.

In this study with relatively mild disease we judged these classes to be sufficient. CE defined by one of the radiologists was considered sufficient for overall classification. Further abnormalities in radiological features were also recorded. Separate scoring was performed on scans of the whole lung and in the upper, middle, and lower zones of the lung.

\section{Spirometry}

All lung function tests were carried out in a specialized clinic by an experienced team of three persons. Lung function $\left(\mathrm{FEV}_{1}, \mathrm{VC}\right.$ and lung diffusion capacity for carbon monoxide; DLco) was measured according to American Thoracic Society $[10,11]$ using a Sensormedics Vmax Encore system (SensorMedics; Yorba Linda, CA, USA). FEV was compared to the largest obtained VC, and individuals with an obstructive pattern also performed a new test 15 minutes after bronchodilation.

\section{Smoking}

Self-reported cigarette smoking was assessed at the clinical examination and quantified as pack years. No smoking exposure was defined as $<5$ pack years.

\section{Statistical Methods}

The characteristics of subjects with and without centrilobular emphysema were presented as medians for continuous variables and proportions for categorical data. The Mann-Whitney U-test and Pearson's chi-square tests were used to calculate the p-values.

The sample was categorized into four sex-specific similarly proportioned quartiles, according to the PD15 -values for the whole lung and for the upper lung separately. One-way analysis of variance was used to compare the continuous variables across the quartiles. P-values less than 0.05 were considered statistically significant. We also present p-values between 0.05 and 0.10 as tendencies. For all statistical calculations SPSS ver. 10 (SPSS Inc. Chicago, U.S.) was used.

\section{Results}

The mean age of the included 133 subjects ( 47 men and 86 women) was 60.7 ( \pm 8.2 years, range: $47-81)$. Of them, 27 (20\%) were considered to have centrilobular emphysema. Of these 27 , one was classified as GOLD stage 0 , thirteen as stage 1 , eleven as stage 2 , and two as GOLD stage 3.

In 17 subjects (13\%) both readers defined the presence of CE. In 30 of the subjects there was a disagreement on the classification (Table 1). Of the remaining subjects, $2 / 27$ subjects were visually assessed as paraseptal emphysema, and 1/27 as panacinar emphysema.

Subject characteristics (personal data, lung function, and smoking habits) according to visual assessment ( $\mathrm{CE}$ or No $\mathrm{CE}$ ) are given for each group in Table 2. $\mathrm{FEV}_{1}, \mathrm{FEV}_{1} / \mathrm{FVC}, \mathrm{DL}_{\mathrm{CO}}$, and smoking showed statistically significant differences between subjects with and without emphysema. The group with emphysema tended to have higher RV/ 


\begin{tabular}{|l|l|l|l|}
\hline & Class Number & Percent \\
\hline 1 & $\begin{array}{l}\text { Centrilobular emphysema parenchymal } \\
\text { destruction }\end{array}$ & $6 / 14$ & $4 / 10$ \\
\hline 2 & Distended parenchyma/very even emphysema & $14 / 26$ & $10 / 18$ \\
\hline 3 & Both (1 and 2) & $21 / 8$ & $15 / 6$ \\
\hline 4 & All centrilobular emphysema (1 and 3) & $27 / 22$ & $19 / 16$ \\
\hline 5 & Normal & $97 / 92$ & $69 / 65$ \\
\hline 6 & Not valid for classification & $3 / 1$ & $2 / 0,7$ \\
\hline 7 & Different opinion & 30 & 21 \\
\hline
\end{tabular}

Table 1: Classifications are presented in the form "radiologist one/radiologis two" both for numbers and percentages. Class 4 and 7 was not original class, but constructed afterwards.

\begin{tabular}{|c|c|c|c|c|c|}
\hline & \multicolumn{4}{|c|}{ Centrilobular emphysema } & \multirow{3}{*}{ P-value } \\
\hline & \multicolumn{2}{|l|}{ No } & \multicolumn{2}{|l|}{ Yes* } & \\
\hline & $\mathbf{N}$ & Median & $\mathbf{N}$ & Median & \\
\hline Age (years) & 106 & 59.5 & 27 & 61 & 0.29 \\
\hline Men, n (\%) & 106 & $34(32)$ & 27 & $13(48)$ & 0.18 \\
\hline $\mathrm{BMI}\left(\mathrm{kg} / \mathrm{m}^{2}\right)$ & 106 & 24.3 & 27 & 23.5 & 0.22 \\
\hline Height (m) & 106 & 1.68 & 27 & 1.70 & 0.85 \\
\hline $\begin{array}{l}\text { DLco }(\mathrm{mmol} / \mathrm{min} / \\
\mathrm{kPa})\end{array}$ & 106 & 21.3 & 27 & 16.1 & $<0.001$ \\
\hline Smokers (\%) & 106 & $32(30)$ & 27 & $16(59)$ & 0.010 \\
\hline Packyears & 99 & 8.5 & 27 & 31 & $<0.001$ \\
\hline FEV $1, \%$ of $P N$ & 106 & 95 & 27 & 80 & 0.018 \\
\hline FVC,$\%$ of PN & 106 & 114 & 27 & 112 & 0.44 \\
\hline FEV1/FVC & 106 & 0.68 & 27 & 0.63 & $<0.001$ \\
\hline RV/TLC & 104 & 0.39 & 27 & 0.44 & 0.084 \\
\hline No COPD & $26(25 \%)$ & -- & $1(3.7 \%)$ & -- & 0.003 \\
\hline GOLD 1 & $51(48 \%)$ & -- & $13(48 \%)$ & -- & \\
\hline GOLD 2 & $28(26 \%)$ & -- & $11(41 \%)$ & -- & \\
\hline GOLD 3 & $1(0.9 \%)$ & -- & $2(7.4 \%)$ & -- & \\
\hline
\end{tabular}

Visually rated as centrilobular emphysema by at least one (out of 2) readers.

${ }^{\ddagger} \mathrm{P}$-values calculated using Mann-Whitney U-test for continuous variables or chisquare test for dichotomous variables.

Table 2: Characteristics of subjects with and without centrilobular emphysema.

TLC ratio $(\mathrm{p}=0.084)$.

Quantitative CT measures of lung density in relation to visually assigned CE status are given in Table 3. For the whole lung, CE subjects showed significantly lower lung density scores than subjects without CE, both for relative area of emphysema (RA-950) and 15th percentile density (PD15). RA-910 for the whole lung was not significantly different between subjects with and without CE. The ratio between upper and lower lung was significantly different for RA-950, but not for RA-910 or PD15.

The computer derived lung density measurements were only partially concordant with the visual assessment in identifying the same individual as having centrilobular emphysema. This disconnect between the computer generated mean levels of lung density (HU as an index of emphysema disease), and the patterns of emphysema observable in images of the lung, occurred frequently. Computerised assessment identified 26/106 centrilobular emphysema free subjects as exhibiting PD15 scores less than the median PD15 score of subjects with visual assigned CE (median CE: $-932 \mathrm{HU}=68 \mathrm{~g} / \mathrm{l}$, non CE range -933 to -949 $\mathrm{HU}=68-51 \mathrm{~g} / \mathrm{l})$. Of these 26 subjects 15 further showed comparable relative area of emphysema $<\mathrm{RA}-950 \mathrm{HU}$ scores to $\mathrm{CE}$ subjects (median $\mathrm{CE} \%<-950 \mathrm{HU}=6.6 \%$, non $\mathrm{CE}$ range $=6.6-14.2 \%$ ). In terms of GOLD guideline definition, $17 / 26$ of these patients were GOLD stage 1, three were GOLD stage 2 , and four subjects were GOLD stage 3 .

\begin{tabular}{|l|l|l|l|}
\hline & \multicolumn{2}{l}{ Centrilobular emphysema } & \multirow{2}{*}{ Pes (N=27) } \\
\cline { 2 - 3 } & No (N=106) & P-value \\
\cline { 2 - 3 } & Median & Median & \\
\hline RA-910 whole lung & 20.2 & 27.3 & 0.096 \\
\hline RA-910 upper & 20.8 & 36.3 & 0.004 \\
\hline RA-910 middle & 19.9 & 27.6 & 0.21 \\
\hline RA-910 lower & 19.6 & 24.9 & 0.21 \\
\hline RA-950 whole lung & 2.31 & 6.63 & $<0.001$ \\
\hline RA-950 upper & 2.39 & 7.22 & $<0.001$ \\
\hline RA-950 middle & 2.30 & 5.02 & 0.001 \\
\hline RA-950 lower & 2.34 & 5.68 & 0.004 \\
\hline PD15 whole lung & -917 & -932 & 0.010 \\
\hline PD15 upper & -916 & -933 & $<0.001$ \\
\hline PD15 middle & -916 & -924 & 0.078 \\
\hline PD15 lower & -916 & -925 & 0.091 \\
\hline
\end{tabular}

Table 3: Quantitative CT measures of lung density given as PD15\% (in HU), RA910 and RA-950 (both in percent below) in relation to centrilobular emphysema, assessed in the whole lung, as well as for different regions of the lung.

\begin{tabular}{|c|c|c|c|c|c|}
\hline & \multicolumn{4}{|c|}{ Whole lung: Sex-specific quartiles of PD15 } & \multirow{3}{*}{$\mathbf{P}$} \\
\hline & Q1 & Q2 & Q3 & Q4 & \\
\hline $\mathrm{N}$ & 32 & 34 & 34 & 33 & \\
\hline PD15 men & $<-938$ & $-938--929$ & $-929--914$ & $>-913$ & \\
\hline PD15 women & $<-929$ & $-929--916$ & $-915--901$ & $>-900$ & \\
\hline Age, years & 62.9 & 61.7 & 60.0 & 58.5 & 0.02 \\
\hline Men, $\%$ & 34 & 35 & 35 & 36 & \\
\hline Smoker,\% & 44 & 21 & 35 & 45 & 0.57 \\
\hline Pack-yrs & 17.8 & 15.4 & 19.2 & 18.4 & 0.68 \\
\hline FEV1,\% PN & 87 & 93 & 88 & 90 & 0.84 \\
\hline $\mathrm{FVC}, \% \mathrm{PN}$ & 118 & 116 & 109 & 109 & 0.01 \\
\hline FEV1/FVC & 0.60 & 0.66 & 0.66 & 0.68 & $<0.001$ \\
\hline $\begin{array}{l}\text { DLco, }(\mathrm{mmol} / \\
\mathrm{min} / \mathrm{kPa})\end{array}$ & 19 & 22 & 21 & 22 & 0.09 \\
\hline RV/TLC & 0.41 & 0.40 & 0.41 & 0.40 & 0.52 \\
\hline BMI & 23.0 & 23.8 & 25.3 & 26.5 & $<0.001$ \\
\hline $\begin{array}{l}\text { Centrilobular } \\
\text { emphysema, (\%) }\end{array}$ & 38 & 15 & 14 & 15 & 0.04 \\
\hline
\end{tabular}

Table 4: Smoking, lung function measures and biomarkers in relation to sexspecific quartiles of PD15

\begin{tabular}{|c|c|c|c|c|c|}
\hline & \multicolumn{4}{|c|}{$\begin{array}{l}\text { Upper third of the lung: Sex-specific quartiles of } \\
\text { PD15 }\end{array}$} & \multirow{3}{*}{$P$} \\
\hline & Q1 & Q2 & Q3 & Q4 & \\
\hline $\mathrm{N}$ & 32 & 34 & 34 & 33 & \\
\hline $\begin{array}{l}\text { PD15, upper } \\
\text { third men }\end{array}$ & $<-938$ & $\begin{array}{l}-937 \text { to } \\
-929\end{array}$ & $\begin{array}{l}-928 \text { to } \\
-916\end{array}$ & $>-914$ & \\
\hline $\begin{array}{l}\text { PD15, upper } \\
\text { third women }\end{array}$ & $<-930$ & $\begin{array}{l}-930 \text { to } \\
-916\end{array}$ & $\begin{array}{l}-916 \text { to } \\
-902\end{array}$ & $>-902$ & \\
\hline Age (yrs) & 62.2 & 62.6 & 60.1 & 58.1 & 0.021 \\
\hline Men\% & 34 & 35 & 35 & 36 & \\
\hline $\begin{array}{l}\text { Current } \\
\text { smoker\% }\end{array}$ & 47 & 29 & 26 & 42 & 0.68 \\
\hline Pack-years & 20.8 & 15.0 & 18.1 & 17.3 & 0.65 \\
\hline FEV1,\% PN & 88 & 94 & 88 & 88 & 0.72 \\
\hline FVC, $\%$ PN & 117 & 118 & 109 & 108 & 0.005 \\
\hline FEV1/FVC & 0.62 & 0.65 & 0.66 & 0.68 & 0.003 \\
\hline $\begin{array}{l}\mathrm{DLco},(\mathrm{mmol} / \\
\mathrm{min} / \mathrm{kPa})\end{array}$ & 18.6 & 22.1 & 20.4 & 22.2 & 0.063 \\
\hline RV/TLC & 0.41 & 0.40 & 0.41 & 0.40 & 0.60 \\
\hline BMI & 23.1 & 24.6 & 25.2 & 25.6 & 0.001 \\
\hline $\begin{array}{l}\text { Centrilobular } \\
\text { emphysema (\%) }\end{array}$ & 41 & 21 & 8.6 & 12 & 0.003 \\
\hline
\end{tabular}

Table 5: Upper third of the lungs: Smoking, lung function measures and biomarkers in relation to sex-specific quartiles of PD15. 
The relationships between the cut off (in HU) for PD15 in quartiles (standardized for sex) for the whole lung, smoking and physiological measures of lung function are presented in Table 4. The proportion with centrilobular emphysema was 38\% in the group with lowest PD15, as compared to approximately $15 \%$ in the PD15-quartiles $2-4$. There was no significant relationship between current smoking or pack-years and PD15. FEV 1 was similarly unrelated to PD15. DLCO tended to be lower in subjects with low density (i.e. low PD15). In an additional analysis the relationships between PD15 and centrilobular emphysema were slightly weakened when PD15 was adjusted for lung volume (not shown). Corresponding analyses were also done for the upper third of the lung only. However, the relationships where only slightly improved compared to using PD15 for the whole lung (Table 5).

A multiple linear regression model was used to explore variables associated with PD15 (Table 6). BMI and sex were significantly associated with PD15. Of the lung function measures, $\mathrm{FEV}_{1} / \mathrm{FVC}$ (low values) and FVC (high values) were associated with low PD15, as could be expected, but there was no relationship between smoking and PD15 in the upper third of the lungs. Neither DLco, FEV (\% PN), nor RV/TLC were associated with PD15 in this model. The results were essentially the same if the PD15 of the upper third of the lung was used.

\section{Discussion}

In the present study computerised methods and visual assessment of computed tomography (CT) scans were compared in a population based study of COPD, to explore the relationships between CT findings, emphysema, smoking, and decreased pulmonary function. The purpose was to assess if quantitative measures could be helpful in early differentiation of risk for COPD.

In centrilobular emphysema the alveolar walls are destroyed starting at the centre of the lobule and the respiratory bronchioles are expanded. This sub-type occurs more commonly in the upper lobes and is closer related to cigarette smoking and COPD than other forms [12].

Computed tomography (CT) is increasingly used for the diagnosis of emphysema. Automatic methods provide qualitative and quantitative estimates of emphysema by acquiring point by point (by voxel position) attenuation measurements that identify locations in the lung with low density. Speed, repeatability and low cost are obvious advantages. Visual inspection by a radiologist has other benefits: a radiologist can visually recognize patterns and spatial distributions of low attenuation and map distributions of disease, especially for other findings than emphysema, in a way that most current automatic algorithms cannot [13]. This is also considered the most likely reason to the discrepancy between quantitative and qualitative measures in the present study. In 1984

\begin{tabular}{|l|l|l|l|l|}
\hline & \multicolumn{2}{l}{ PD15, whole lung } & \multicolumn{2}{l|}{ PD15, Upper } \\
\cline { 2 - 5 } & Beta (+SE) & P & Beta (+SE) & p \\
\hline Age (per 1 year) & $-0.36(0.22)$ & 0.11 & $-0.79(0.32)$ & 0.017 \\
\hline Sex (women vs men) & $12(4.0)$ & 0.004 & $8.8(4.9)$ & 0.075 \\
\hline BMl (per 1 kg/m²) & $1.7(0.60)$ & 0.004 & $1.9(0.74)$ & 0.011 \\
\hline Pack-years (per 1 year) & $-0.04(0.10)$ & 0.70 & $-0.16(0.13)$ & 0.21 \\
\hline FEV1/FVC (per 1\%) & $0.97(0.22)$ & $<0.001$ & $0.90(28)$ & 0.002 \\
\hline FEV1 (per 1\%) & $0.15(0.11)$ & 0.17 & $0.12(0.13)$ & 0.36 \\
\hline FVC (per 1\%) & $-0.21(0.12)$ & 0.08 & $-0.21(0.15)$ & 0.16 \\
\hline $\begin{array}{l}\text { DLco (per mmHg/kPa } \\
\text { x min-1) }\end{array}$ & $0.33(0.37)$ & 0.37 & $0.71(0.45)$ & 0.11 \\
\hline RV/TLC (per 1\%) & $-0.31(0.28)$ & 0.26 & $0.16(0.34)$ & 0.65 \\
\hline
\end{tabular}

Table 6: Results from multiple linear regressions with PD15 as dependent variable. Age, Sex, BMI, and pack-years were entered in the first step. The lung function measures were then individually adjusted for the variables in the first step.
Hayhurst et al. [14] demonstrated that quantitative CT measurements using a density threshold could be used to detect the presence of emphysema. Müller et al. [15] showed the highest correlation between pathology and CT-measures using the threshold RA-910 [\%]. Gevenois et al. $[16,17]$ recommended the use of RA-950 for thin-section CT. Both these thresholds, as well as the fixed ratio PD15 have been used in several studies for the purpose of assessing the degree of emphysema [18-22]. Further, these measures have been used obtained both at maximum inspiration and maximum expiration [23]. Both for the upper part and for whole lung PD15 was recommended by an expert group to be used in longitudinal studies [24].

PD15 showed higher values (more dense tissue) for females than males. This is in concordance with findings of Dransfield et al. [25] who reported larger areas below $-950 \mathrm{HU}$ for the same GOLD stage of COPD in men than in women. The reason for this is unclear; maybe this is associated with the generally slightly lower ratio between $\mathrm{FEV}_{1}$ and FVC (i.e. that they are more obstructive), which could lead to a slight over inflation, or the more extensive growth of the male thorax during adolescence after the lung tissue is formed during the fetal period.

Our results show that centrilobular emphysema, assessed by two experienced radiologists, was significantly associated with smoking history, air flow limitation, DLco and GOLD-stage. On the other hand, PD15 showed no consistent relationship with smoking or DLco when measured in the whole lung, and relationships were only slightly improved when measured in the upper third of the lung. Using a fixed cut off the present study showed better agreement between visual scoring and the cut off at $-950 \mathrm{HU}$ than for $-910 \mathrm{HU}$.

Even if it is widely accepted that smoking is a major causal risk factor of COPD and emphysema, previous studies of the relationships between smoking and lung density have not been unambiguous. In the present study, there was no significant relationship between pack-years and tissue density in smokers without COPD. One of the problems is that smoking itself tends to increase density of the lung parenchyma (by inflammation, cells, fluid etc), masking signs of emphysema, and making density less correlated to actual loss of alveolar septa. Hence the time relation between exposure and assessment is important [2628]. In a sub-study from the ECLIPSE trial [29], there was a weak, but statistically significant relationship between pack-years and RA-950 in subjects with COPD. However, also in that study current smoking was strongly associated with higher densities, which outweighed the effects of decades of heavy smoking. This masking effect seems greater in subjects which has not yet acquired significant airflow limitation.

In our study of COPD the PD15 and other computerised algorithms did not show a better correlation to other measures of COPD than visual assessments. The reason is probably due to better pattern recognition in visual assessment, which is supported by findings by Gietema et al. [30]. Our findings are in concordance with a recent meta-analysis [31] in which emphysema detected visually on CT was found to be independently associated with increased odds of lung cancer, but not emphysema that was automatically detected. On the other hand another recent meta-analysis of these measures showed significant correlation between CT measurements of emphysema and airflow obstruction, with the strongest association found between CT emphysema measurements and the ratio FEV1/FVC, thus confirming correlations between morphology and function in COPD patients [32].

The physiological measures of lung function showed very different patterns for visually assessed centrilobular emphysema and measured low lung density. Visual assessment was associated with significantly 
reduced FEV1, FEV1/FVC, and DLco, and although not significantly, increased RV/TLC. This is what could be expected from a clinical point of view. In contrast, low lung density was associated with increased FVC. CT scans was performed at maximum inspiration, which in spirometric terms means at total lung capacity (TLC). However, as usual in routine CT scanning, the lung volume during scanning was not measured spirometrically, i.e. we have no means to investigate if the lung volume at scanning differed from TLC measured by spirometry, and slight differences in level of inflation could result in this correlation since more inflation will result in less density generally. If we could have corrected for lung volume at scanning this would have been an advantage.

Another thing that can improve accuracy is correcting density values using the $\mathrm{HU}$ value measured in the trachea. However, an automatic internal $\mathrm{HU}$ value calibration using tracheal air could not be performed in the present study due to the thick slices and the resulting challenges to accurately segment the airway tree.

There was an observed strong correlation between lung density and BMI, also seen previously [33]. While lung density is also artifactually influenced by scattered $\mathrm{x}$-ray radiation, this contribution is expected to be relatively low when using a 4 slice CT scanner with a small cone beam angle. Even though low BMI is associated with low density, this association occurs in predominantly in advanced COPD disease, while in this group with only three subjects with GOLD Stage 3 (none stage 4). The alternative approach chosen to adjust for these effects was to include BMI as a co-variate in the multi-variate analysis.

To conclude, in this population based study measuring lung attenuation by CT in subjects with relatively mild degree of COPD, both quantitative automated assessment methods and visual scoring provided similar classifications of disease. Overall, both lung function and smoking showed closer statistical correlation to visual scoring than the software driven assessments. However, the advantages of using automated evaluation are several including cost and the non-biased but robust assessments of regions throughout the whole lung.

\section{Acknowledgements}

The authors thank Jenny Hallberg, formerly PhD student within the project for her part of data collection. The team of technicians; Mrs Daniels, Mrs Norgren and Mrs Magnusson skilfully collected data (lung function, and questionnaires) at Dpt. of Clinical Physiology, Södersjukhuset, and Stockholm.

\section{Declaration of Interests}

Dr Gerhardsson de Verdier, and Dr Nordenmark are employees atAstraZeneca, Dr Engström, Dr Fehniger and Dr Dahlbäck were employed at AstraZeneca at the time of the study. The authors have nothing else to report.

\section{References}

1. Rabe KF, Hurd S, Anzueto A, Barnes PJ, Buist SA, et al. (2007) Global strategy for the diagnosis, management, and prevention of chronic obstructive pulmonary disease: GOLD executive summary. Am J Respir Crit Care Med 176: 532-555.

2. Wang Z, Gu S, Leader JK, Kundu S, Tedrow JR, et al. (2013) Optimal threshold in CT quantification of emphysema. Eur Radiol 23: 975-984.

3. Desai SR, Hansell DM, Walker A, MacDonald SL, Chabat F, et al. (2007) Quantification of emphysema: a composite physiologic index derived from CT estimation of disease extent. Eur Radiol 17: 911-918.

4. Mets OM, Murphy K, Zanen P, Gietema HA, Lammers JW, et al. (2012) The relationship between lung function impairment and quantitative computed tomography in chronic obstructive pulmonary disease. Eur Radiol 22: 120-128.

5. Coxson HO (2008) Quantitative chest tomography in COPD research chairman's summary. Proc Am Thorac Soc 5: 874-877.
6. Mets OM, de Jong PA, van Ginneken B, Gietema HA Lammers JW (2012) Quantitative computed tomography in COPD: possibilities and limitations. Lung 190: 133-145.

7. Lichtenstein P, De Faire U, Floderus B, Svartengren M, Svedberg P, et al. (2002) The Swedish Twin Registry: a unique resource for clinical, epidemiological and genetic studies. J Intern Med 252: 184-205.

8. Svartengren M, Engström G, Anderson M, Hallberg J, Edula G, et al. (2009) Twins studies as a model for studies on the interaction between smoking and genetic factors in the development of chronic bronchitis. Biochem Soc Trans 37: 814-818.

9. Hallberg J, lliadou A, Anderson M, de Verdier MG, Nihlén U, et al. (2010) Genetic and environmental influence on lung function impairment in Swedish twins. Respir Res 11: 92.

10. Miller MR, Hankinson J, Brusasco V, Burgos F, Casaburi R, et al. (2005) Standardisation of spirometry. Eur Respir J 26: 319-338.

11. Macintyre N, Crapo RO, Viegi G, Johnson DC, van der Grinten CP, et al. Standardisation of the single-breath determination of carbon monoxide uptake in the lung. The European respiratory journal 26: 720-35.

12. Anderson AE Jr, Foraker AG (1973) Centrilobular emphysema and panlobular emphysema: two different diseases. Thorax 28: 547-550.

13. COPDGene CT Workshop Group, Barr RG, Berkowitz EA, Bigazzi F, Bode F et al. (2012) A combined pulmonary-radiology workshop for visual evaluation of COPD: study design, chest CT findings and concordance with quantitative evaluation. COPD 9: 151-159.

14. Hayhurst MD, MacNee W, Flenley DC, Wright D, McLean A, et al. (1984) Diagnosis of pulmonary emphysema by computerised tomography. Lancet 2 : 320-322.

15. Müller NL, Staples CA, Miller RR, Abboud RT (1988) "Density mask". An objective method to quantitate emphysema using computed tomography. Chest 94: 782-787.

16. Gevenois PA, de Maertelaer V, De Vuyst P, Zanen J, Yernault JC (1995) Comparison of computed density and macroscopic morphometry in pulmonary emphysema. Am J Respir Crit Care Med 152: 653-657.

17. Gevenois PA, De Vuyst P, de Maertelaer V, Zanen J, Jacobovitz D, et al. (1996) Comparison of computed density and microscopic morphometry in pulmonary emphysema. Am J Respir Crit Care Med 154: 187-192.

18. Kinsella M, Müller NL, Abboud RT, Morrison NJ, DyBuncio A (1990) Quantitation of emphysema by computed tomography using a "density mask" program and correlation with pulmonary function tests. Chest $97: 315-321$

19. Arakawa A Yamashita Y, Nakayama Y, Kadota M, Korogi H, et al. (2001) Assessment of lung volumes in pulmonary emphysema using multidetector helical CT: comparison with pulmonary function tests. Computerized medical imaging and graphics: the official journal of the Computerized Medical Imaging Society 25: 399-404

20. Madani A, Keyzer C, Gevenois PA (2001) Quantitative computed tomography assessment of lung structure and function in pulmonary emphysema. Eur Respir J 18: 720-730.

21. Cederlund K, Tylén U, Jorfeldt L, Aspelin P (2002) Classification of emphysema in candidates for lung volume reduction surgery: a new objective and surgically oriented model for describing CT severity and heterogeneity. Chest 122: 590596.

22. Stavngaard T, Shaker SB, Bach KS, Stoel BC, Dirksen A (2006) Quantitative assessment of regional emphysema distribution in patients with chronic obstructive pulmonary disease (COPD). Acta Radiol 47: 914-921.

23. Akira M, Toyokawa K, Inoue Y, Arai T (2009) Quantitative CT in chronic obstructive pulmonary disease: inspiratory and expiratory assessment. AJR Am J Roentgenol 192: 267-272.

24. Newell JD Jr, Hogg JC, Snider GL (2004) Report of a workshop: quantitative computed tomography scanning in longitudinal studies of emphysema. Eur Respir J 23: 769-775.

25. Dransfield MT, Washko GR, Foreman MG, Estepar RS, Reilly J, et al. (2007) Gender differences in the severity of CT emphysema in COPD. Chest 132 464-470.

26. Wollmer P, Albrechtsson U, Brauer K, Eriksson L, Jonson B, et al. (1986) Measurement of pulmonary density by means of X-ray computerized 
Citation: Anderson M, Engström G, Nordenmark LH, Mohlkert D, Rouzbeh E, et al. (2015) Detection of Smoking Induced Emphysema: Visual Scoring versus Computerised Algorithms J Pulm Respir Med 5: 291. doi:10.4172/2161-105X.1000291

tomography. Relation to pulmonary mechanics in normal subjects. Chest 90 : 387-391.

27. Ashraf H, Lo P, Shaker SB, de Bruijne M, Dirksen A, et al. (2011) Short-term effect of changes in smoking behaviour on emphysema quantification by $\mathrm{CT}$. Thorax 66: 55-60.

28. Shaker SB, Stavngaard T, Laursen LC, Stoel BC, Dirksen A (2011) Rapid fall in lung density following smoking cessation in COPD. COPD 8: 2-7.

29. Grydeland TB, Dirksen A, Coxson HO, Pillai SG, Sharma S, et al. (2009) Quantitative computed tomography: emphysema and airway wall thickness by sex, age and smoking. Eur Respir J 34: 858-865.
30. Gietema HA, Muller NL, Fauerbach PV, Sharma S, Edwards LD, et al. (2011) Quantifying the extent of emphysema: factors associated with radiologists' estimations and quantitative indices of emphysema severity using the ECLIPSE cohort. Academic radiology 18: 661-71.

31. Smith BM, Pinto L, Ezer N, Sverzellati N, Muro S, et al. (2012) Emphysema detected on computed tomography and risk of lung cancer: a systematic review and meta-analysis. Lung Cancer 77: 58-63.

32. Xie X, de Jong PA, Oudkerk M, Wang Y, ten Hacken NHT, et al. (2012 Morphological measurements in computed tomography correlate with airflow obstruction in chronic obstructive pulmonary disease: systematic review and meta-analysis. European radiology 22: 2085-2093.

33. Coxson HO, Dirksen A, Edwards LD, Yates JC, Agusti A, et al. (2013) The presence and progression of emphysema in COPD as determined by CT scanning and biomarker expression: a prospective analysis from the ECLIPSE study. Lancet Respir Med 1: 129-136. 